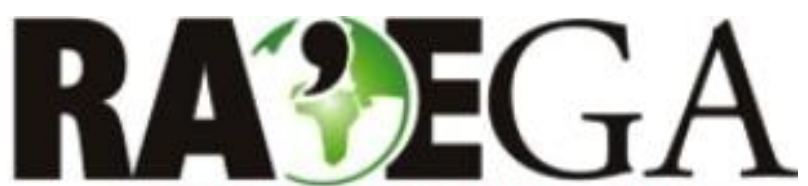

O ESPAÇO GEOGRÁFICO EM ANÁLISE

\title{
O INTERESSE DOS GEÓGRAFOS PELOS SONS: ALINHAMENTO TEÓRICO E METODOLÓGICO PARA ESTUDOS DAS PAISAGENS SONORAS
}

\section{THE INTEREST OF GEOGRAPHERS BY THE SOUNDS: THEORETICAL AND METHODOLOGICAL ALIGNMENT FOR STUDIES OF SOUNDSCAPES}

\author{
Lawrence Mayer Malanski ${ }^{1}$
}

\section{RESUMO}

A elaboração deste artigo objetivou o alinhamento teórico e metodológico de diferentes autores que contribuem para os estudos das experiências dos espaços e da paisagem sonora. Para tanto, adotou-se a perspectiva humanista da geografia fundamentada, sobretudo, em ideias de Maurice Merleau-Ponty. O método utilizado para sua elaboração foi de revisão narrativa de literatura, o qual não esgotou as fontes de informações e submeteu a interpretação das mesmas à subjetividade do autor. Os resultados revelam a possibilidade do estudo do mundo sonoro a partir de suas experiências individuais, o que perpassa a percepção dos espaços acústicos até a conformação de um mundo vivido. A percepção converte os objetos sonoros em eventos / signos o que, juntamente com a intersubjetividade, resulta na paisagem sonora. Além de signos, esses eventos podem ser compreendidos como sinais, símbolos, ruídos e sons fundamentais, que juntos caracterizam e dão identidades aos lugares. Assim, a paisagem sonora pode ser definida como uma formação mental intencional construída a partir da relação corporal do indivíduo com o mundo sonoro objetivo e com o outro. Ao tratar da experiência espacial, considera-se a escala no nível da percepção dos fenômenos sonoros nos locais, o que favorece o desenvolvimento de diferentes técnicas de coleta de informações em campo, tais como as caminhadas sonoras, as gravações, a elaboração de mapas sonoros pessoais e a posterior organização de catálogos de sons e de preferências sonoras.

PALAVRAS-CHAVE: Geografia humanista; Fenomenologia; Percepção; Paisagem

\section{ABSTRACT}

This article's preparation aimed to theoretical and methodological alignment of different authors contributing to the study of experiences of spaces and soundscape. For this purpose, it was adopted the humanist perspective of geography based specially in Maurice Merleau-Ponty ideas. The method used for its preparation was literature review, which has not exhausted the sources of information and has interpretation submitted to the author's perspective. The results show the possibility of the sound world study from their individual experiences, which runs throught the perception of acoustic spaces to the formation of a living world. Perception converts sonic objects in events/signs, which together with the intersubjectivity result in the soundscape. Besides signs, these events can be understood as signals, symbols, places. Thus, soundscape can be defined as an intentional mental training built from the body relation between individuals and the objective sound world and the other one. When dealing with spacial experience, it was taken in consideration the scale at the level of the perception of sound phenomena in places, which favors the development of different information gathering techniques such as soundwalks, field recordings, development of personal sound maps and subsequent organization of catalogs of sound and sound preferences.

KEY-WORDS: Humanistic Geography; Phenomenology; Perception; Landscape

Recebido em: 01/04/2016

Aceito em: 31/10/2016

\footnotetext{
${ }^{1}$ Instituto Federal do Paraná, Londrina/PR e-mail: lawrence.malanski@ifpr.edu.br
} 


\section{MALANSKI,L.M. \\ O INTERESSE DOS GEÓGRAFOS PELOS SONS: ALINHAMENTO TEÓRICO E METODOLÓGICO PARA ESTUDOS DAS PAISAGENS SONORAS}

\section{INTRODUÇÃO}

O som, enquanto qualidade sensível, faz parte do arranjo dos espaços e, quando percebido, participa da composição de paisagens e da identidade dos lugares. Contudo, o mundo sonoro é comumente tratado de modo superficial ou como problema ambiental (destacando, assim, seus aspectos negativos) por profissionais e pesquisadores neles interessados. Pouco se faz no sentido de explorar esse mundo a partir da perspectiva das experiências humanas.

Sobretudo nas grandes cidades ocidentais, as pessoas vivem em espaços carregados de sensações visuais e imersas em um aparente caos sonoro. A predileção pelo sentido da visão revela a existência de uma certa "cultura do olho" (SCHAFER, 2011) que distancia os indivíduos das outras formas de se relacionar com o mundo e demonstra um real desperdício da capacidade humana de experienciar. Logo, nessas cidades, a tendência é que os moradores possuam baixo nível de consciência dos sons e sofram um grau elevado de privação sensorial (PORTEOUS; MASTIN, 1985).

Numa perspectiva histórica, os geógrafos modernos despenderam atenção ao mundo sonoro, mas raramente desenvolveram trabalhos específicos sobre ele. Alexander von Humboldt, por exemplo, em meados do século XIX, descreveu alguns sons percebidos por ele durante suas inúmeras viagens, assim como buscou explicações científicas a respeito de suas origens, como se nota neste trecho do livro Views of nature:

O aparecimento súbito, em 30 de Janeiro de 1811, da ilha de Sabrina, no grupo dos Açores, foi o precursor dos terremotos terríveis que, mais para o oeste, abalaram, de maio de 1811 a junho de 1813, quase ininterruptamente, as primeiras das Antilhas, em seguida, as planícies do Ohio e Mississippi, e, por último, as costas opostas da Venezuela ou Caracas. Trinta dias após a destruição total da bela capital da província, houve uma erupção do vulcão São Vicente, inativo por muito tempo, nas ilhas próximas das Antilhas. Um fenômeno notável acompanhou esta erupção: no momento da explosão, que ocorreu em 30 de abril de 1811, um terrível barulho subterrâneo foi ouvido na América do Sul, ao longo de um distrito de mais de 35.000 milhas quadradas. Os habitantes das margens do Apure, na confluência do Kio Mula, e aqueles que vivem na costa do mar remoto da Venezuela, concordaram em comparar esse som ao ruído de artilharia pesada. A distância entre a confluência do Rio Kio Nula com o Apure (pelo qual eu entrei no Orinoco) para o vulcão de São Vicente, medida em linha reta, nada menos do que 628 milhas. Esse ruído certamente não foi propagado pelo ar, e deve ter surgido de alguma causa subterrânea profunda; sua intensidade foi, de resto, dificilmente maior nas margens do Mar do Caribe, perto do vulcão em fúria, que no interior do país na bacia do Apure e do Orinoco (HUMBOLDT, 1850, p.361, tradução nossa).

Também, Johannes Gabriel Granö, geógrafo finlandês entusiasta dos trabalhos de Humboldt e Siegfried Passarge, dedicou-se à descrição e comparação de paisagens e ao mapeamento de regiões, o que comumente incluía suas experiências de movimentos, sons e trajetórias de locais remotos da Finlândia e da Estônia (POCOCK, 1989; LINKOLA, 2006), como se nota neste trecho do livro Pure geography:

[...] rios navegáveis fluem através da terra do sul para o norte. Eles nascem nas altas geleiras das montanhas e viajam com sons trovejantes e cobertos de ondas brancas e fluem através dos desfiladeiros profundos das serras e continuam com suas águas turvas através de estepes secas e, finalmente, juntam-se calmamente às águas geladas do distante Oceano Ártico, no norte (GRANÖ, 1929 apud BUTTIMER, 2010, p.24, tradução nossa).

No entanto, foi com o desenvolvimento das geografias da percepção e humanista na década de 1960 e a compreensão das categorias de lugar e paisagem a partir de pressupostos fenomenológicos que as experiências do mundo sonoro passaram a receber maior atenção. Além disso, muitos dos trabalhos sobre o tema foram realizados por geógrafos influenciados pelas ideias de Raymond Murray Schafer, músico e 


\section{MALANSKI,L.M. \\ O INTERESSE DOS GEÓGRAFOS PELOS SONS: ALINHAMENTO TEÓRICO E METODOLÓGICO PARA ESTUDOS DAS PAISAGENS SONORAS}

ecologista que elaborou o conceito de paisagem sonora e sugeriu diferentes práticas de campo.

O desenvolvimento do conceito de paisagem sonora na geografia favoreceu a exploração da dimensão sonora dos espaços por meio de características capazes de refletir preferências pessoais, valores culturais e organizações sociais. No entanto, com a leitura de trabalhos recentes sobre o assunto, nota-se que pouco se discute em relação a esse conceito, sendo que muitos apenas o aplicam sem os devidos cuidados, o que pode resultar em incompatibilidade ou mesmo contradição teórica e metodológica.

Nesse contexto, com a elaboração deste artigo objetivou-se o alinhamento teórico e metodológico de diferentes autores que, de algum modo, contribuem para os estudos das experiências dos espaços e da paisagem sonora. Para tanto, adotou-se princípios da geografia humanista e ideias desenvolvidas pelo filósofo Maurice Merleau-Ponty a fim de contribuir com geógrafos humanistas interessados na exploração do mundo sonoro.

\section{MÉTODO}

Este artigo foi elaborado a partir de revisão narrativa de bibliografia dos temas fenomenologia, percepção do som e do espaço, paisagem sonora, paisagem, lugar e geografia humanista. Para tanto, foram consultados livros de destaque nessas temáticas como Fenomenologia da percepção de Merleau-Ponty, Tratado de los objetos musicales do compositor Pierre Schaeffer, A afinação do mundo de Schafer, Espaço e lugar e Topofilia do geógrafo YiFu Tuan e ¿De qué tiempo es este lugar? do urbanista Kevin Lynch.

Também, foram consultados diversos artigos, sobretudo de geógrafos, encontrados por meio de buscas realizadas a partir de descritores relacionados ao tema de pesquisa nas línguas portuguesa e inglesa em mecanismos virtuais como Google Academics, Microsoft Academic e Scielo. Dentre os artigos utilizados encontram-se de geógrafos como John Drever, Carlos Fortuna, Jorge Gaspar, David Holmes, Teresa Barata
Salgueiro, David Lowenthal, Marcos Alberto Torres e Salete Kozel, além do antropólogo Steven Feld.

Por se tratar de uma revisão narrativa de bibliografia as fontes de informações não foram esgotadas e a seleção e interpretação das mesmas estiveram sujeitas à subjetividade do autor.

\section{RESULTADOS E DISCUSSÕES}

\subsection{EXPERIÊNCIA DO MUNDO SONORO}

As experiências humanas do mundo sonoro ocorrem em espaços e tempos determinados e podem ser contempladas pelo viés humanista da geografia. A geografia humanista se caracteriza pelo aporte filosófico na fenomenologia e no existencialismo sobretudo, o que permite aos geógrafos despertar interesse por aspectos subjetivos relacionados aos espaços, lugares e paisagens, tais como significados, valores e propósitos de ações (GOODEY; GOLD, 1986; CAPEL, 1987).

Nesse contexto teórico, considera-se o mundo como o espaço da existência, da experiência humana, no qual ocorrem as ligações teóricas, práticas, afetivas e simbólicas que definem a geograficidade (DARDEL, 2011). Tal experiência se desenvolve a partir do corpo, um organismo de cores, odores, sons e aparências táteis sensível a objetos e a outros corpos no espaço (CÓRDOBA, 2012). Logo, ele é o centro de perspectiva e a expressão que possibilita aos indivíduos frequentarem e compreenderem o mundo em que vivem (MERLEAU-PONTY, 2011; CÓRDOBA, 2012). Nesse sentido, cabe ao fenomenólogo a descrição dessas experiências corporificadas (CERBONE, 2014).

$\mathrm{O}$ acesso do indivíduo ao mundo é feito através da percepção, responsável por apresentar intencionalmente à consciência humana objetos sensíveis e outros indivíduos (MERLEAU-PONTY, 2011; SOKOLOWSKI, 2014). Conforme Merleau-Ponty (2011), a estrutura espacial é percebida de modo holístico e integrado, isto é, ela se comunica com todos os sentidos de uma vez. Essa sinergia permite, por exemplo, que se possa "ouvir cores" e "ver sons". 


\section{MALANSKI,L.M. \\ O INTERESSE DOS GEÓGRAFOS PELOS SONS: ALINHAMENTO TEÓRICO E METODOLÓGICO PARA ESTUDOS DAS PAISAGENS SONORAS}

Logo, a percepção conforma um mundo vivido que depende de indivíduos que o percebem e que nele se relacionam. Sobretudo a intersubjetividade, um tipo de intencionalidade que atua na experiência de outros indivíduos, conforma e unifica o espaço de vivência individual ao inserir nesse processo uma estrutura rica e diversificada de aspectos subjetivos (CÓRDOBA, 2012; SOKOLOWSKI, 2014).

Para Merleau-Ponty (2011), o som, enquanto um fenômeno físico e uma qualidade sensível do mundo objetivo, é registrado pelos tímpanos no ato da sensação e serve de ponto de partida para a percepção. Nesse sentido, a percepção supera a sensação ao interpretá-la, fazendo com que a qualidade sensível do objeto sonoro não possa mais ser experimentada imediatamente. Assim, conforme o autor, o mundo sonoro objetivo confia aos ouvidos mensagens que devem ser conduzidas, depois decifradas pela consciência de modo a reproduzir um pensamento de mundo. Logo, a consciência é sempre consciência de um objeto ou corpo; cada intenção tem seu objeto ou corpo intencionado (MERLEAU-PONTY, 2011; SOKOLOWSKI, 2014).

Essa perspectiva fenomenológica diverge da concepção dual entre objeto sonoro e indivíduo proposta por fenomenólogos aportados em Edmund Husserl, como Schaeffer, que partiram da concepção de um mundo sonoro objetivo em si que apenas agiria sobre o ouvido humano (SCHAEFFER, 2003; MERLEAU-PONTY, 2011). Tal mundo poderia ser acessado através da redução fenomenológica transcendental realizada por um sujeito metafísico capaz de suspender todos os juízos de valores estabelecidos (CERBONE, 2014).

De acordo com a concepção de Schaeffer (2003), o objeto sonoro corresponde ao objeto fenomenológico sensível que independe de qualidades simbólicas de referência, estando, portanto, isolado de seu contexto. A extensão do espaço pela qual se propaga um determinado objeto sonoro é chamada de espaço acústico (FORTUNA, 1998). Conforme Fortuna (1998), o centro desse espaço é ocupado por um agente emissor determinado e, à medida que o som emitido por ele se espalha, mistura-se com outros até ter sua origem obscurecida e indeterminada. Essa concepção motiva o desenvolvimento de pesquisas a respeito das características físicas espectrais dos sons, o que contribui com os trabalhos de áreas como acústica, medicina e música.

De outro modo, a perspectiva fenomenológica de Merleau-Ponty rompe com o mundo em si ao propor o sistema eu / outro / objetos, indicando uma desconfiança a respeito da legitimidade da redução fenomenológica transcendental ao considerar a experiência do sujeito enquanto ser concreto (MERLEAU-PONTY, 2011; CERBONE, 2014).

Esse sistema sugere a conformação do mundo sonoro a partir da relação entre o indivíduo, os objetos sonoros / espaços acústicos e outros indivíduos. Da percepção de diferentes espaços acústicos e da intersubjetividade resulta a paisagem sonora (FORTUNA, 1998), uma formação mental intencional construída a partir da relação corporal do indivíduo com o mundo sonoro objetivo e com o outro.

Para a formação da paisagem sonora, a percepção converte os objetos sonoros em eventos dependentes de qualidades simbólicas, semânticas e estruturais que se relacionam com um contexto maior (SCHAFER, 2011). Isso demonstra que a modalidade perceptiva de ouvir é influenciada por respostas afetivas e emocionais dadas aos objetos (CERBONE, 2014). Esse evento sonoro é capaz de despertar emoções e pensamentos nos indivíduos que vão além das sensações imediatas, o que confere a cada espaço de existência características de intimidade, monumentabilidade, convite ou rejeição, hospitalidade ou hostilidade (SCHAFER, 2011).

Conforme Fortuna (1998), a experiência individual do mundo sonoro e a intersubjetividade caracterizam a paisagem sonora como fundamentalmente antropocêntrica. Para esse autor, os geógrafos humanistas interessados nos estudos dessas paisagens podem explorar esse mundo de modo 


\section{MALANSKI,L.M. \\ O INTERESSE DOS GEÓGRAFOS PELOS SONS: ALINHAMENTO TEÓRICO E METODOLÓGICO PARA ESTUDOS DAS PAISAGENS SONORAS}

a descrever as experiências dele. Logo, a descrição de uma paisagem sonora envolve sempre um ato de atribuição de sentido, pois os significados dos sons são sempre relativos e dizem respeito às experiências de vida individuais e sociais.

Ao possuírem significados referenciais e adicionarem sistemas de valores culturais, os eventos sonoros, de acordo com Schafer (2011), tornam-se signos. Além de signos, esses eventos podem ser compreendidos como sinais, símbolos, sons fundamentais e ruídos. Todos esses componentes caracterizam e estruturam o mundo sonoro vivido.

$\mathrm{Na}$ perspectiva de Schafer (2011), os sinais correspondem aos sons particulares que se destacam por terem significados específicos e por comumente atraírem a atenção dos ouvintes. Eles frequentemente estimulam respostas comportamentais diretas e permitem a transmissão de mensagens àqueles indivíduos capazes de interpretá-las. São exemplos de sinais sonoros os apitos, buzinas, campainhas e sirenes.

Ainda conforme o autor, os símbolos sonoros possuem conotações mais ricas se comparados aos sinais sonoros, pois são capazes de despertar emoções e pensamentos nos ouvintes. Quando um símbolo possui importância histórica e características únicas em um contexto social e cultural de uma comunidade pode ser considerado um marco sonoro (SCHAFER, 2011). Por isso, um marco sonoro, uma vez identificado, necessita de proteção. Nesse sentido, conforme Lowenthal (1976), as gravações podem evitar que esses sons significativos se percam por completo com o passar do tempo. Logo, uma vez perdido e na ausência de testemunhas auditivas diretas ou indiretas, a recuperação de um marco sonoro ou outro som específico se torna impossível.

Já os ruídos, para Schafer (2011), possuem definições variadas, mas comumente são associados aos sons não desejados de intensidade forte e com o caos auditivo. Nesse sentido, existem leis que tratam da redução dos ruídos e estabelecem limites permissíveis numa escala de decibéis, principalmente em áreas urbanas e industriais. Para o autor, o estudo das legislações referente aos ruídos pode revelar diferentes atitudes culturais em relação às fobias e transtornos acústicos de uma certa comunidade.

Os sons de fundo, por sua vez, são aqueles ouvidos continuamente por indivíduos de uma sociedade contra o qual os signos, sinais e símbolos também são percebidos (SCHAFER, 2011). Eles podem ser emitidos por fontes naturais não biológicas como o vento e a água (geofonia), por animais, como as aves (biofonia) e pelas pessoas, suas técnicas e tecnologias, como motores a combustão e tráfego de veículos (antropofonia), comumente associados aos ruídos (KRAUSE, 2013).

Os sons de fundo desempenham função essencial na maneira como as sociedades se expressam e podem revelar informações significativas a respeito da qualidade ambiental (SCHAFER, 2011; KRAUSE, 2013). Historicamente, os espaços acústicos urbanos, por exemplo, tendem a ser formados por emissões de origem antropofônica, que, ao serem percebidos, formam paisagens sonoras ambíguas, transitórias e aparentemente sem histórias, raízes e identidade definida (FORTUNA, 1998; SCHAFER, 2011; KRAUSE, 2013).

Essa perspectiva entre sons de fundo, signos, sinais e símbolos sonoros revela uma analogia à estrutura comum nos estudos da teoria da Gestalt (SCHAFER, 2011). Esta teoria envolve a relação de um indivíduo perceptor com o mundo sensível a partir da qual se organiza espontaneamente a percepção (MERLEAUPONTY, 2011). Assim, a descrição mais básica da experiência perceptiva envolve a perspectiva entre a figura e o fundo (CERBONE, 2014). No entanto, para ser percebido, um objeto ou corpo precisa estar no meio de outra coisa, precisa estar em meio a um campo (MERLEAU-PONTY, 2011).

Tratando-se do mundo sonoro objetivo, esse campo corresponde ao espaço onde coexistem os diferentes espaços acústicos produzidos e emitidos por diferentes ações (FORTUNA, 1998). Da percepção desse campo resulta a paisagem sonora, que, por sua vez, 


\section{O INTERESSE DOS GEÓGRAFOS PELOS SONS: ALINHAMENTO TEÓRICO E METODOLÓGICO PARA ESTUDOS DAS PAISAGENS SONORAS}

pode ser organizada mentalmente em sons de figura ou de fundo em decorrência de processos de aculturação, estados das mentes e das relações pessoais com o campo, sobretudo no que diz respeito às situações de moradores locais ou visitantes (SCHAFER, 2011) (FIGURA 01).

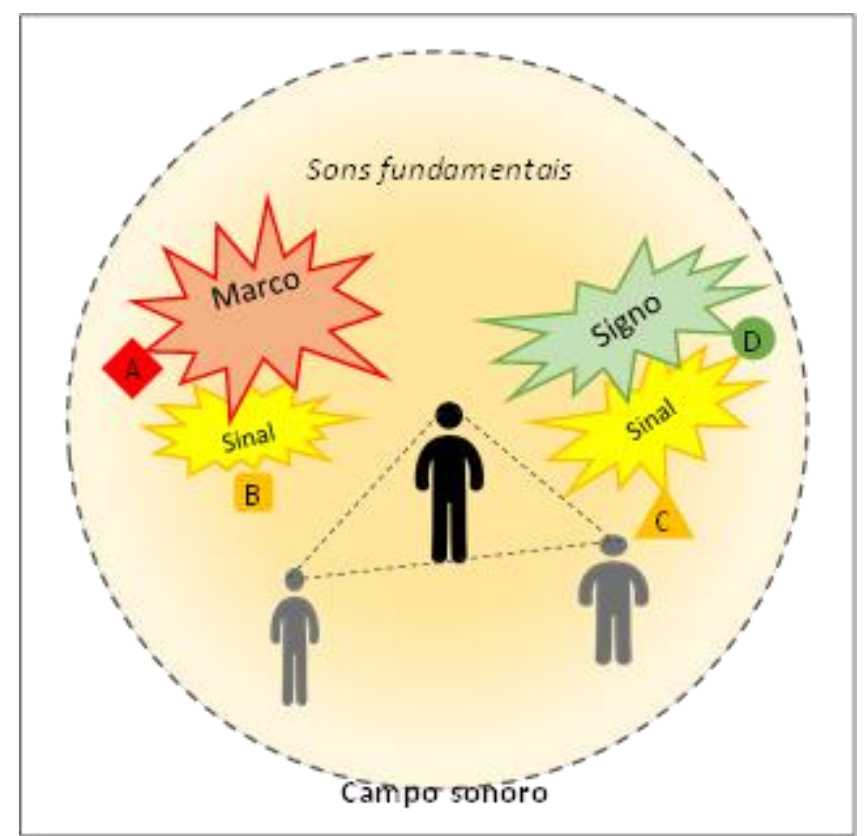

Figura 01 - Organização da Paisagem Sonora - A organização da paisagem sonora é feita a partir da percepção dos sons em um campo sonoro, o que os transforma em sons de fundo e de figura, como sinais, signos e símbolos. Também, precisa-se considerar as relações intersubjetivas entre o indivíduo perceptor e outros indivíduos. As letras A, B, C e D representam diferentes agentes emissores de sons. Organização: o autor (2017).

A partir da perspectiva figura / fundo / campo, as paisagens sonoras foram classificadas em relação à qualidade por Schafer (2011) em alta-fidelidade ou baixa-fidelidade. Para esse autor, uma paisagem de alta-fidelidade possui perspectiva figura / fundo na qual os sons percebidos se sobrepõem menos frequentemente e são claramente identificáveis em razão do baixo nível de ruído. Ainda, desse modo, ela apresenta riqueza de detalhes. De outro modo, para ele, nas paisagens de baixa fidelidade os sinais sonoros são obscurecidos em uma quantidade de sons superdensa, redundantes e contínua não havendo, assim, perspectiva figura / fundo. Logo, nessas paisagens a organização dos sons percebidos é complexa, pois há um "congestionamento" deles e uma grande quantidade de informações que pouco emerge com clareza.

\subsection{TEMPO, LUGAR E PAISAGEM}

Conforme Fortuna (1998), sobretudo nas áreas rurais, os espaços acústicos foram gradativamente sendo transformados em decorrência do desenvolvimento tecnológico e da mecanização. Isso comumente resultou na substituição das paisagens sonoras de altafidelidade pelas de baixa. Enquanto nas cidades, as paisagens sonoras sempre tenderam à baixa fidelidade em decorrência de espaços acústicos repletos de sons de tráfego de veículos e do desenvolvimento das atividades humanas espacialmente concentradas (FORTUNA, 1998; TUAN, 2012).

Logo, numa perspectiva espaciotemporal, compreende-se, de modo geral, que a percepção dos espaços acústicos rurais tendem a conformar paisagens sonoras de maior fidelidade se comparado aos espaços urbanos, 


\section{O INTERESSE DOS GEÓGRAFOS PELOS SONS: ALINHAMENTO TEÓRICO E METODOLÓGICO PARA ESTUDOS DAS PAISAGENS SONORAS}

assim como a percepção dos espaços acústicos durante as noites conformam paisagens de maior fidelidade se comparado às percepções durante os dias (LOWENTHAL, 1976; I FONT, 1985; SCHAFER, 2011). O mesmo é valido para o que se refere aos tempos antigos em relação aos modernos, pois a medida que os espaços são modificados, seus sons são modificados também (LOWENTHAL, 1976; FORTUNA, 1998).

Assim, a experiência do mundo depende de perspectivas invariavelmente relacionadas à posição do corpo no espaço e no tempo e da subjetividade do indivíduo perceptor (CREMASCO, 2009; MERLEAU-PONTY, 2011). Tal experiência ocorre e é estruturada a partir do estado do agora, pois o espaço onde ocorre a experiência existe no presente (LYNCH, 1975). Esse estado configura-se como uma classificação imediata das experiências pessoais subjetivas que se parece muito com o ordenamento espacial imediato (LYNCH, 1975; TUAN, 2013).

Já o passado é organizado a partir de acontecimentos selecionados e arranjados em esquemas de modo que seja possível identificálos e memorá-los sem a necessidade de recapitular toda uma história, o que o torna parte integrante do sentido de identidade (LYNCH, 1975; LOWENTHAL, 1998). Para identificar e memorar o passado, precisam-se de marcas como fotografias, sons e cheiros, ou de formas de sentir diretamente o solo nativo para evocar lugares, outras pessoas e memórias (LOWENTHAL, 1976; GASPAR, 2001; KATO, 2009; KRAUSE, 2013). Assim, por exemplo, em meio ao "burburinho cacofônico" das cidades e indústrias, a biofonia, a geofonia e o próprio silêncio podem demonstrar relações com o passado e um modo de vida pastoril (LOWENTHAL, 1976). Logo, as experiências passadas podem encarnar o caráter dos espaços de modo a influenciar suas percepções, o que confere finalidade e valor à existência humana (LOWENTHAL, 1998).

A ideia de futuro, por sua vez, parte de uma simples projeção até se transformar em algo criador que também guia as ações do presente, persistindo, nesse caso, as fantasias e os sonhos (LYNCH, 1975).
Também, de acordo com Tuan (2013), a partir da relação inseparável entre espaço e tempo pode-se definir a categoria de lugar, entendida como uma pausa no movimento pelo espaço. Por meio dessa pausa as pessoas percebem e conhecem o espaço circundante a partir de suas posições relativas e atribuem a ele valores e significados. Logo, tanto o espaço quanto o lugar são forjados no decurso de horas de acordo com ambiguidades, sentimentos de afeição, temores, medos e maneiras de agir das pessoas (MELLO, 2014). Quando esses atributos remetem a laços afetivos com os lugares tem-se o sentimento de topofilia, que permite conexões pessoais afetivas e simbólicas do entorno com a experiência do espaço (LYNCH, 1975; TUAN, 2012). Para o sentimento contrário, ou seja, aversão ou medo entre pessoas e lugares tem-se a topofobia (TUAN, 2012).

Igualmente, tem-se o sentimento de topofonofilia quando existem sentimentos afetivos das pessoas para com os lugares a partir de seus sons e, de modo contrário, o de topofonofobia, sendo que esse último pode levar os ouvintes à ansiedade, medo, dor, confusão e isolamento social (DREVER, 2015).

É nos lugares, ainda, onde se desenvolvem os movimentos dos corpos, itinerários, passos e gestos, fundidos às rotinas espaçotemporais relacionadas ao cotidiano das pessoas (MELLO, 2014). Isso pode ser compreendido como o "balé-do-lugar", que ocorre em diferentes espaços e tempos e se caracteriza por uma dinâmica regular e diversificada que marca o ritmo próprio de cada lugar (SEAMON, 1979). Nesse sentido, os sons também conferem ao indivíduo perceptor as sensações de dinâmica do espaço e de imersão nos lugares frequentados. Logo, a medida que as rotinas se desenvolvem ao longo das horas do dia, essas sensações são alteradas de acordo com o ritmo de cada lugar.

Oposto ao lugar, o deslugar caracterizase como um espaço padronizado, essencialmente funcional e impessoal que desfavorece a pausa no movimento humano e sugere às pessoas o esquecimento da relação espaçotemporal (TUAN, 


\section{MALANSKI,L.M. \\ O INTERESSE DOS GEÓGRAFOS PELOS SONS: ALINHAMENTO TEÓRICO E METODOLÓGICO PARA ESTUDOS DAS PAISAGENS SONORAS}

2013; RELPH, 2014). Por esse motivo, até mesmo as paisagens sonoras de shopping centers, restaurantes fast-foods e aeroportos (exemplos de deslugares) podem ser desprovidas de atrativos e significados (TUAN, 2013).

No entanto um mesmo espaço pode ser compreendido simultaneamente como lugar e deslugar à medida que ambos se equilibram entre particularidades e uniformidades construídas pelas experiências dos seus frequentadores (RELPH, 2014). Logo, as subjetividades relacionadas a esses espaços variam em relação, sobretudo, à frequência e o propósito de seus usos.

Se a pausa no movimento pelo espaço confere estabilidade ao lugar, falta isso à paisagem, pois ela pode se alterar a partir da mudança de perspectiva de um observador, isto é, a partir do seu movimento (TUAN, 2013). Nesse contexto, a perspectiva fenomenológica permite compreender a paisagem como uma construção individual elaborada a partir da experiência espacial, o que exige a presença humana no espaço e no tempo (SALGUEIRO, 2001; DARDEL, 2011). Assim, a paisagem compreendida pelo geógrafo humanista é o resultado da capacidade humana de interagir com o espaço através do corpo (I FONT, 1985). Portanto, ela é essencialmente antropocêntrica e seus estudos precisam destacar seus significados ou de alguns de seus elementos, como os sons (SALGUEIRO, 2001).

\subsection{RECURSOS PARA O ESTUDO DAS PAISAGENS SONORAS}

Por tratar da experiência do mundo sonoro objetivo, as pesquisas desenvolvidas por geógrafos humanistas comumente consideram a escala no nível da percepção e concepção dos fenômenos sonoros nos locais, isto é, a mesoescala (CASTRO, 2000; GASPAR, 2001). Com isso, a realidade percebida e concebida torna-se uma projeção do real feita a partir de perspectivas individuais (CASTRO, 2000).

Essa adoção da mesoescala e a valorização do local destaca práticas de investigação de campo, através das quais são observadas tanto as dimensões físicas / materiais dos espaços, quanto as representações das experiências e do imaginário individual e social (ALAMI; DESJEUX; GARABUAU-MOUSSAOURI, 2010). Para tanto, são necessárias diferentes técnicas de coleta e tratamento das informações, sobretudo, de caráter projetivo e construtivo, e observatório e descritivo.

No contexto da observação e descrição do mundo sonoro, enquadram-se as caminhadas sonoras, caracterizados como caminhadas exploratórias cujo objetivo principal é ouvir os espaços acústicos no nível dos detalhes (SCHAFER, 2011; MCCARTNEY; PAQUETTE, 2012; BERNAT, 2014). Os participantes dessas caminhadas se inserem em espaços onde a vida cotidiana se desenvolve e têm suas experiências valorizadas, pois precisam desenvolver audições atentas durante os trajetos percorridos a fim de atender os objetivos estabelecidos para a exploração (DREVER, 2009; SCHAFER, 2011).

Caso o interesse da pesquisa seja os sons de um espaço determinado, é interessante a realização de caminhadas sonoras em horários, períodos, dias da semana ou mesmo épocas do ano distintas, a fim de explorar a diversidade de situações relacionadas aos ritmos dos lugares, isto é, às rotinas espaçotemporais do cotidiano das pessoas em diferentes contextos.

Essas caminhadas podem ocorrer por motivações políticas, ecológicas, sociais, estéticas, históricas ou musicais, por exemplo, e acontecer individualmente ou em grupo; em silêncio ou com diálogo entre os participantes; com roteiros, formas de registro e durações predeterminados ou não; com ou sem a mediação de equipamentos eletrônicos como gravadores de áudio, GPS e câmeras fotográficas e filmadoras digitais (DREVER, 2009; MCCARTNEY; PAQUETTE, 2012).

Caso os sons dos espaços onde se realizou uma caminhada sonora tenham sido gravados, os arquivos obtidos tornam-se importantes registros para documentação e análise posterior (DREVER, 2009; HOLMES, 2016). No entanto, ao serem ouvidas indiretamente, isto é, fora do contexto espaciotemporal original 


\section{MALANSKI,L.M. \\ O INTERESSE DOS GEÓGRAFOS PELOS SONS: ALINHAMENTO TEÓRICO E METODOLÓGICO PARA ESTUDOS DAS PAISAGENS SONORAS}

(SCHAEFFER, 2003), sem o auxílio direto dos demais órgãos perceptivos a respeito do espaço percebido, as gravações resultam em novas composições de paisagens sonoras. Por isso são importantes os registros de fotografias, vídeos, descrições e comentários feitos em campo, pois eles podem contribuir para a caracterização do contexto no qual as gravações foram feitas.

Feld (2014) indicou que as gravações comumente são feitas de modo móvel ou estacionário. No primeiro caso, durante a caminhada, o pesquisador move-se com o equipamento pelo espaço, enquanto no segundo caso ele necessita permanecer parado. Conforme o autor, durante as gravações móveis podem ser selecionados panoramas sonoros, sendo que, para tanto, o observador permanece parado por entre dois a três minutos de modo a obter um recorte temporal e espacial de um campo sonoro determinado.

Os registros sonoros são feitos por aparelhos profissionais ou semiprofissionais de gravação de áudio em estéreo ou, mesmo, através de aplicativos de smartphones, em um formato de áudio digital como o WAV e o MP3 (HOLMES, 2016). Esses formatos permitem a rápida edição dos arquivos em softwares como o Audacity e a divulgação e disponibilização gratuita deles em mídias digitais como bancos de dados sonoros virtuais (como o Freesound), plataformas on-line de publicação de áudio (como o SoundCloud) ou websites de compartilhamento de vídeos (como o YouTube).

Há, ainda, a possibilidade de inserir os arquivos de áudio em bases cartográficas digitais on-line, como o Google Maps, Bing Maps e Map Maker. Isso resulta em mapas sonoros virtuais que permitem ouvir as gravações e situar com precisão cartográfica os locais onde elas foram feitas. $\mathrm{Na}$ Internet existem diversos mapas sonoros com finalidades distintas e que utilizam diferentes recursos tecnológicos, como: Soundcities, Favourite Sounds, Radio Aporee, com sons de diversas localidades do mundo e SP SoundMap, com sons de diferentes localidades da cidade de São Paulo.

Para facilitar a organização das caminhadas e das gravações de campo o pesquisador pode fazer uso de registros escritos que contenham um número de identificação / registro, data, localização, condições do tempo, período do dia, hora do início e término da caminhada / gravação, duração da caminhada / gravação, equipamento utilizado para a gravação, formato e qualidade da gravação e se foram obtidas (e quantas foram) imagens e feitos vídeos (HOLMES, 2016). Também, podem ser anotadas descrições e comentários a respeito das caminhadas e gravações, inclusive, com o uso de um croqui ou mapa (FIGURA 02). 
MALANSKI,L.M.

O INTERESSE DOS GEÓGRAFOS PELOS SONS: ALINHAMENTO TEÓRICO E METODOLÓGICO PARA ESTUDOS DAS PAISAGENS SONORAS

Registro de caminhada sonora/gravações de campo

\begin{tabular}{|c|c|c|}
\hline Número de registro: & Data: & Localizaçāo: \\
\hline \multicolumn{3}{|l|}{ Condições do tempo: } \\
\hline \multicolumn{3}{|c|}{ Período do dia: ( ) manhã ( ) tarde ( ) noite } \\
\hline \multicolumn{2}{|l|}{ Início da gravação: } & \multirow{2}{*}{ Duração: } \\
\hline \multicolumn{2}{|l|}{ Término da gravação: } & \\
\hline Imagens: & & os: \\
\hline
\end{tabular}

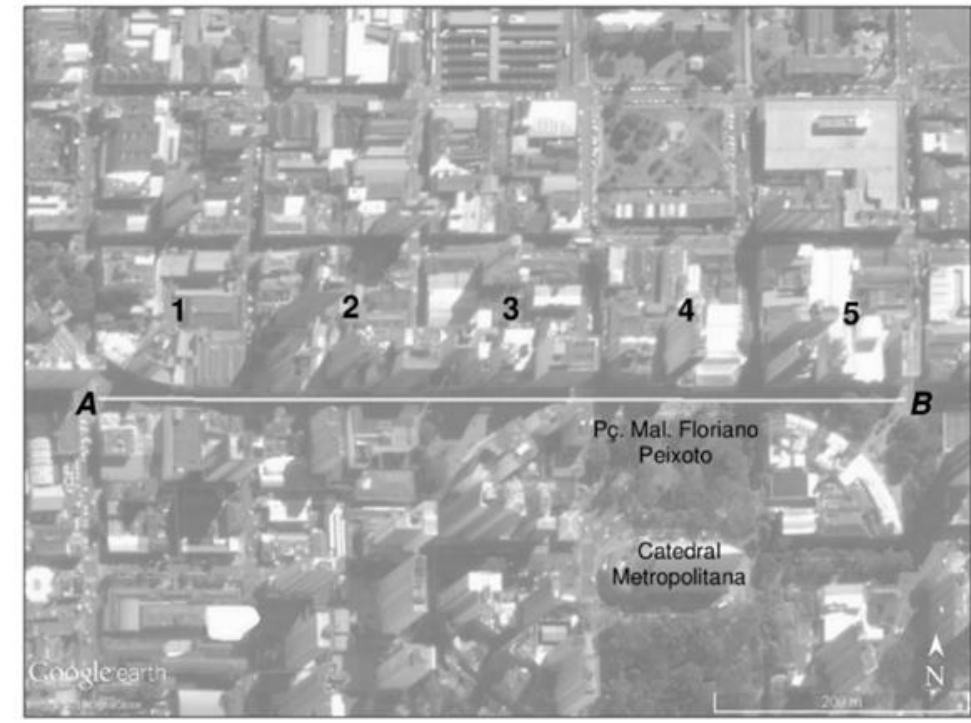

Descrição e comentários

Figura 02 - Exemplo de Ficha de Registro de uma Caminhada Sonora / Gravações de Campo - Além das lacunas destinadas às informações referentes ao registro e organização da ficha (parte superior), observa-se um croqui elaborado a partir de imagens de satélite (no caso da região central cidade de Londrina, Paraná, com destaque para o calçadão) com a marcação dos pontos de início e término de uma caminha ( $\mathrm{A}$ e $\mathrm{B}$ respectivamente) e a numeração das quadras do calçadão da cidade, além do espaço para a inserção da descrição e de comentários da caminhada sonora e gravações de campo. Fonte: Adaptado de Holmes (2016). 
MALANSKI,L.M.

\section{O INTERESSE DOS GEÓGRAFOS PELOS SONS: ALINHAMENTO TEÓRICO E METODOLÓGICO PARA ESTUDOS DAS PAISAGENS SONORAS}

Com a posterior audição das gravações, os sons nelas presentes podem ser classificados e catalogados pelo pesquisador formando um tipo de catálogo de sons (SCHAFER, 2011). Na elaboração desse material consideram-se, sobretudo, os aspectos físicos dos sons, tais como as formas de ocorrência (isoladas ou repetitivas); se possuem funções específicas (avisos ou alertas sonoros); as categorias a que pertencem em relação às fontes emissoras (biofonia, geofonia ou antropofonia); suas durações e as durações das categorias (em segundos ou minutos); e, ainda, as localizações das fontes emissoras em um croqui (SCHAFER, 2011; HOLMES, 2016). Dependendo da motivação da pesquisa, pode importar, também a intensidade dos sons (em decibéis) (HOLMES, 2016). Esses catálogos, juntamente com as gravações, podem ser utilizados para o registro, análise e comparação das mudanças ocorridas em um determinado campo sonoro ao longo do tempo (horas do dia, meses ou anos) e entre campos sonoros distintos (DREVER, 2009; HOLMES, 2016) (FIGURA 03). 
Catálogo de sons da caminhada sonora

\begin{tabular}{|l|l|l|}
\hline Número de registro: & Data: & Localização: \\
\hline Início da gravação: & \multirow{2}{*}{ Duração: } \\
\hline Término da gravação: & \\
\hline
\end{tabular}

\begin{tabular}{|c|c|c|c|c|}
\hline \multicolumn{5}{|c|}{ ANTROPOFONIA } \\
\hline Som & Ocorrência & Função & $\begin{array}{c}\text { Duração } \\
\text { (seg.) }\end{array}$ & $\begin{array}{c}\text { Duração da } \\
\text { categoria (seg.) }\end{array}$ \\
\hline & & & & \\
\hline & & & & \\
\hline & & & & \\
\hline & & & & \\
\hline & & & & \\
\hline & & & & \\
\hline & & & & \\
\hline & & & & \\
\hline & & & & \\
\hline & & & & \\
\hline & & & & \\
\hline & & $\overline{N I A}$ & & \\
\hline Som & Ocorrência & Função & $\begin{array}{c}\text { Duração } \\
\text { (seg.) }\end{array}$ & $\begin{array}{c}\text { Duração da } \\
\text { categoria (seg.) }\end{array}$ \\
\hline & & & & \\
\hline & & & & \\
\hline & & & & \\
\hline & & & & \\
\hline & & & & \\
\hline & & DNIA & & \\
\hline Som & Ocorrência & Função & $\begin{array}{c}\text { Duração } \\
\text { (seg.) }\end{array}$ & $\begin{array}{l}\text { Duração da } \\
\text { categoria (seg.) }\end{array}$ \\
\hline & & & & \\
\hline & & & & \\
\hline & & & & \\
\hline & & & & \\
\hline & & & & \\
\hline
\end{tabular}

Figura 03 - Exemplo de Ficha para Catálogo de Sons de uma Caminhada Sonora - Além das lacunas destinadas às informações referentes ao registro, notam-se as lacunas destinadas à classificação dos sons das gravações de acordo com a categoria da fonte emissora. Fonte: Adaptado de Holmes (2016).

De outro modo, o pesquisador pode registrar e explorar os aspectos simbólicos orientados pela percepção do campo sonoro através da elaboração de mapas sonoros pessoais (HOLMES, 2016). Esses mapas podem ser elaborados tanto pelo próprio pesquisador a partir de suas experiências espaciais, quanto por outros indivíduos selecionados que estejam frequentando o espaço explorado (BERNAT, 2014). Conforme Seemann (2010), eles são 
MALANSKI,L.M.

\section{O INTERESSE DOS GEÓGRAFOS PELOS SONS: ALINHAMENTO TEÓRICO E METODOLÓGICO PARA}

\section{ESTUDOS DAS PAISAGENS SONORAS}

compreendidos como variações dos mapas mentais e, portanto, destacam-se como representações sígnicas das experiências, ideias e imagens que os indivíduos possuem dos espaços vividos ou imaginados. Após serem elaborados, os mapas precisam ser lidos e interpretados pelo pesquisador, buscando "decifrá-los".

Holmes (2016 sugere que os mapas sonoros pessoais sejam elaborados em uma folha de papel com o traçado de um círculo (representando o campo sonoro percebido) que tenha em seu centro um " $X$ " (simbolizando a posição relativa do observador no mapa) (FIGURA 04). A partir do " $X$ " o mapeador tem a possibilidade de ordenar os signos no mapa de acordo com as distâncias das fontes emissoras dos sons em relação à sua posição. 
Mapeamento pessoal da paisagem sonora

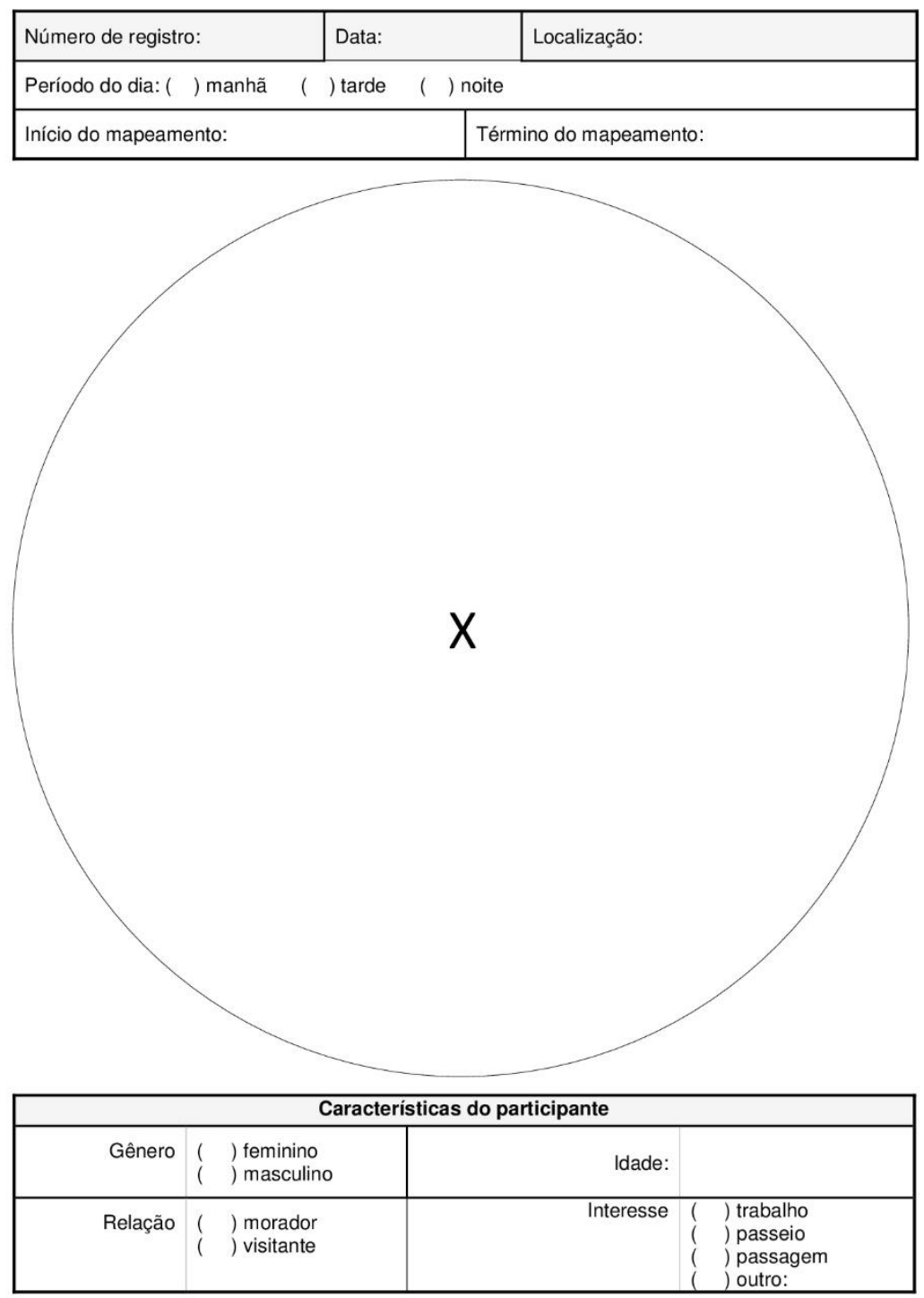

Figura 04 - Exemplo de Ficha para Mapeamento Sonoro Pessoal - Além das lacunas destinadas às informações referentes ao registro e organização da ficha (parte superior) e à caracterização do mapeador (parte inferior), nota-se o espaço destinado para a elaboração do mapa (parte central). Fonte: Adaptado de Holmes (2016).

A opção por esses elementos (sociais, Conforme Holmes (2016), para realizar o mapeamento, o pesquisador tem a possibilidade de ouvir atentamente, ou solicitar ao outro 
MALANSKI,L.M.

\section{O INTERESSE DOS GEÓGRAFOS PELOS SONS: ALINHAMENTO TEÓRICO E METODOLÓGICO PARA ESTUDOS DAS PAISAGENS SONORAS}

indivíduo com a função de mapeador que ouça, os sons por cerca de dois ou três minutos para, então, representá-los no mapa em formas de signos. Em seguida, caso a função de mapeador tenha sido exercida por outro indivíduo que não o pesquisador, pode-se anotar dados que o caracterize para fins de interpretação, tais como gênero, relação com o espaço (se é morador ou visitante), idade e interesse em relação ao espaço (se está a trabalho, passeio, de passagem etc.) (FIGURA 03).

A elaboração do mapa sonoro pode ocorrer em conjunto com a realização de uma entrevista feita com o mapeador (TORRES, KOZEL, 2011). A entrevista pode ser escrita ou gravada e envolver questões referentes às lembranças do entrevistado referentes ao espaço explorado, sua trajetória de vida, suas preferências em relação aos sons agradáveis, desagradáveis e marcantes do espaço percebido. Essas informações podem fomentar, auxiliar ou complementar o processo de leitura e interpretação do mapa sonoro elaborado.

Ainda, o pesquisador é capaz de organizar a partir das análises de diversas entrevistas feitas com indivíduos distintos catálogos de preferências sonoras relativos aos espaços acústicos percebidos (BERNAT, 2014). A partir deles é possível identificar os sons considerados agradáveis e desagradáveis, sentimentos de topofonofilia e topofonofobia e aspectos sonoros simbólicos que conferem identidade aos lugares, por exemplo (SCHAFER, 2011) (FIGURA 05). A partir dos catálogos podem ser elaboradas tabelas, gráficos, esquemas e mapas temáticos que demonstrem as preferências sonoras dos entrevistados. 


\section{Preferências sonoras}

\begin{tabular}{|l|l|l|}
\hline Número de registro: & Data: & Localização: \\
\hline Período do dia: $(\quad)$ manhã $\quad(\quad)$ tarde $\quad(\quad)$ noite \\
\hline Início da entrevista: & Término da entrevista: \\
\hline
\end{tabular}

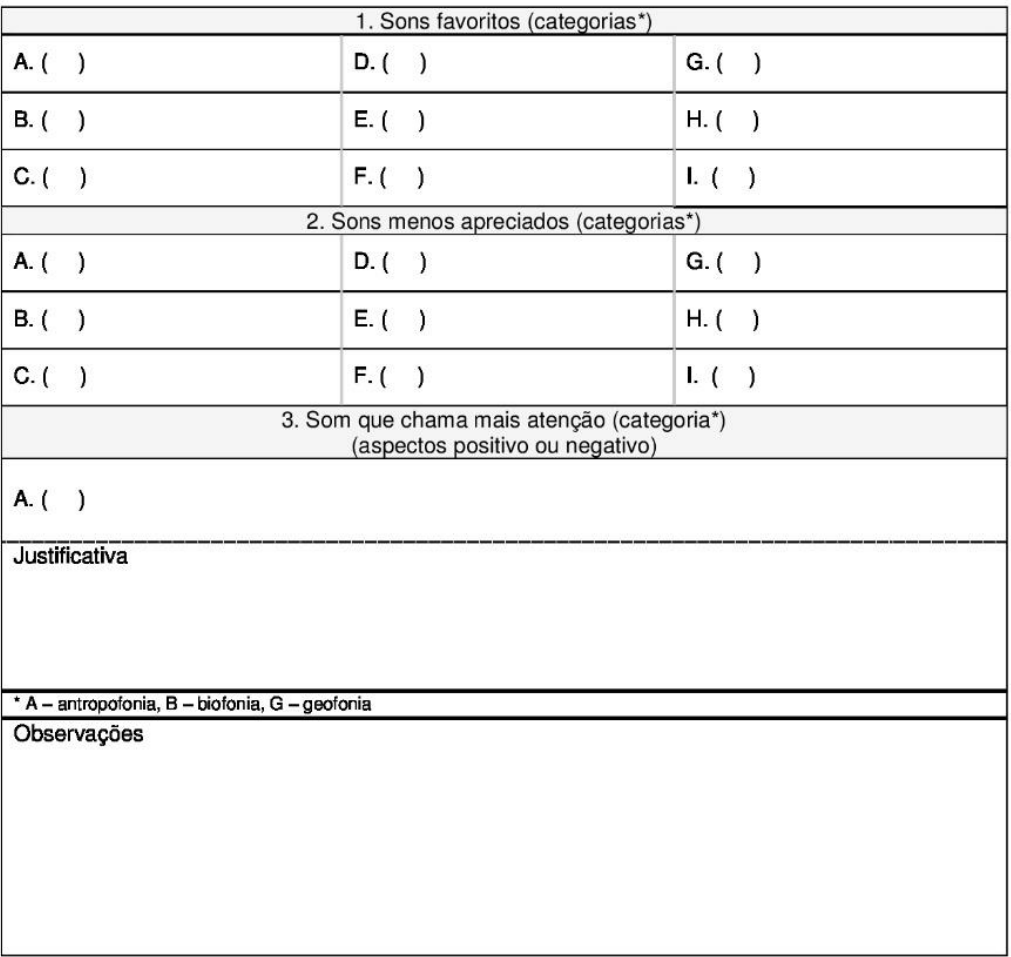

\begin{tabular}{|c|c|c|c|}
\hline \multicolumn{4}{|c|}{ Características do entrevistado } \\
\hline Gênero & $\begin{array}{l}\text { ( ) feminino } \\
\text { ( ) masculino }\end{array}$ & Nascimento: & \\
\hline $\begin{array}{r}\text { Relação com o } \\
\text { campo }\end{array}$ & $\begin{array}{l}\text { ( ) morador } \\
\text { ( ) visitante }\end{array}$ & Interesse & $\begin{array}{l}\text { ( ) trabalho } \\
\text { ( ) passeio } \\
\text { ( ) passagem } \\
\text { ( ) outro: }\end{array}$ \\
\hline
\end{tabular}

Figura 05 - Exemplo de Ficha de Preferências Sonoras - Além das lacunas destinadas às informações referentes ao registro e organização da ficha (parte superior) e à caracterização do entrevistado (parte inferior), notam-se as lacunas destinadas à listagem de sons considerados agradáveis, desagradáveis e ao som que mais chamou atenção do observador. Fonte: O autor (2017).

\section{CONSIDERAÇÕES FINAIS}

Compreender a paisagem sonora a partir de pressupostos fenomenológicos significa considerá-la uma formação mental construída a partir da experiência do mundo sonoro objetivo e de experiências intersubjetivas. A experiência dos 


\section{MALANSKI,L.M. \\ O INTERESSE DOS GEÓGRAFOS PELOS SONS: ALINHAMENTO TEÓRICO E METODOLÓGICO PARA ESTUDOS DAS PAISAGENS SONORAS}

sons ocorre a partir da percepção, esta responsável por apresentar intencionalmente à consciência humana os objetos sonoros que são convertidos em eventos sonoros ao adquirirem significados referenciais.

Ao adquirirem tais significados, os eventos sonoros podem ser compreendidos como signos, sinais, símbolos, sons fundamentais e ruídos que, organizados espontaneamente pela mente, demonstram relações estruturais entre sons de fundo e sons de figura. A partir destas relações as paisagens sonoras são classificadas como sendo de alta-fidelidade ou baixa fidelidade. Também, a partir das paisagens sonoras, é possível identificar e compreender elementos sonoros que caracterizam e dão identidade aos lugares, tanto em relação aos sentimentos de afeição quanto de aversão, medo ou mesmo de impessoalidade.

Essa perspectiva fenomenológica de estudo permite ao geógrafo explorar, descrever e analisar as experiências que conformam o mundo sonoro vivido. Para tanto, ele tem à sua disposição diferentes recursos para registrar, catalogar e comparar os aspectos objetivos do mundo sonoro, como as gravações, os mapas sonoros e os catálogos de sons, bem como para registrar, ler e interpretar representações simbólicas e preferências pessoais referentes às paisagens sonoras, como as caminhadas sonoras, os mapas sonoros pessoais e os catálogos de preferências sonoras.

\section{REFERÊNCIAS BIBLIOGRÁFICAS}

ALAMIS, S.; DESJEUX, D.; GARABUAUMOUSSAOUI, I. Os métodos qualitativos. Petrópolis: Vozes, 2010.

BERNAT, S. Sound in landscape: the main research problems. Dissertations of Cultural Landscape Commission. Lublin, n. 23, p. 89-108, 2014. Disponível em: <http://goo.gl/84ZCF0>. Acesso em: 18/03/2016.

BUTTIMER, A. Humboldt, Granö and Geo-poetics of the Altai. Fennia, Helsinki, n. 188, v. 1, p. 1136, 2010. Disponível em: <http://goo.gl/pfQoO3>. Acesso em: 03/08/2015.
CAPEL, H. Geografia humana y ciencias sociales: una perspectiva histórica. Barcelona: Montesinos Editor, 1987.

CASTRO, I. E. O problema da escala. In: CASTRO, I. E.; GOMES, P. C. C; CORRÊA, R. L. (orgs.). Geografia: conceitos e temas. 2a ed. Rio de Janeiro: Bertrand Brasil, 2000.

CERBONE, D. R. Fenomenologia. Petrópolis: Vozes, 2014.

CÓRDOBA, M. La existencia encarnada del hombre em cuanto signo. Una aproximación semiótica a la corporeidad. Universidad de Navarra, Navarra, 2012. Disponível em: <http://goo.gl/CPXjwN>. Acesso em: 28/12/2015.

CREMASCO, M. V. F. Algumas contribuições de Merleau-Ponty para a psicologia em "Fenomenologia da percepção". Revista da Abordagem Gestáltica, Goiânia, v. 15, n. 1, p. 5154, 2009. Disponível em: <http://goo.gl/7aSJ8X>. Acesso em: 28/12/2015.

DARDEL, É. O homem e a Terra: natureza da realidade geográfica. São Paulo: Perspectiva, 2011.

DREVER, J. Soundwalking: aural excursions into the everyday. In: SAUNDERS, J. (Org.). The ashgate research companion to experimental music. Aldershot: Ashgate, p. 163-192, 2009. Disponível em: <http://goo.gl/dCwmpd>. Acesso em 12/11/2015.

Topophonophobia: the space and place os acute hearing. In: Hearing Landscape Critically: music, place, and the space of sound. Cambridge, 2015. Disponível em: <http://goo.gl/PgCjer>. Acesso em: 02/03/2016.

FELD, S. Pensando na gravação de paisagens sonoras. Música e Cultura, Rio de Janeiro, vol. 9, n. 1, 2014 . Disponível em: <http://goo.gl/oHtzAu>. Acesso em: 08/11/2015.

FORTUNA, C. Imagens da cidade: sonoridades e ambientes sociais urbanos. Revista Crítica de Ciências Sociais, Coimbra, n. 51, p. 21-41, 1998. Disponível em: <https://goo.gl/BWxYX2>. Acesso em: 04/012/2015.

GASPAR, J. O retorno da paisagem à geografia. Finisterra, Lisboa, n. 72, p. 83-99, 2001. Disponível em: <http://goo.gl/3hCDvR>. Acesso em: 03/08/2015.

GOODEY, B.; GOLD, J. Geografia do comportamento e da percepção. Departamento 


\section{MALANSKI,L.M. \\ O INTERESSE DOS GEÓGRAFOS PELOS SONS: ALINHAMENTO TEÓRICO E METODOLÓGICO PARA ESTUDOS DAS PAISAGENS SONORAS}

de Geografia da Universidade Federal de Minas Gerais, Belo Horizonte, edição especial n. 3, p. 721, 1986.

HOLMES, D. Soundscapes: Immersing yourself into the acoustic environment. Disponível em: <http://goo.gl/MHycek>. Acesso em: 19/09/2016.

HUMBOLDT, A. Views of nature: or contemplation on the sublime phenomena of creation. Londres: Harrison and Son, 1850.

I FONT, J. N. El paisatge sonor de la Garrotxa. Revista de Girona, Girona, n. 111, p. 96-102, 1985. Disponível em: <http://goo.gl/yWB6xS>. Acesso em: 10/08/2015.

KATO, K. Soundscape, cultural landscape and connectivity. Sites, Hamilton, v. 6, n. 2, p. 80-91, 2009. Disponível em: <https://goo.gl/KW1wlb>. Acesso em: 04/11/2015.

KRAUSE, B. A grande orquestra da natureza: descobrindo as origens da música no mundo selvagem. Rio de Janeiro: Zahar, 2013.

LINKOLA, H. Broken landscape - J. G. Granö's landscape science from the standpoint of past and present landscape research. The permanent European Conference for the Study of the Rural Landscape. Berlim, 2006. Disponível em: <http://goo.gl/HhMLpQ>. Acesso em: 03/08/2015.

LOWENTHAL, D. El pasado es um país extranõ. Barcelona: Editores Akal, 1998.

. En busca de los sonidos perdidos: ¿Se puede recuperar el paisaje sonoro de nuestros antepasados?. El Correo, Paris, p. 15-17, nov. 1976. Disponível em: <http://goo.gl/1VJf9a>. Acesso em: 26/08/2015.

LYNCH, K. ¿De qué tiempo es este lugar?. Barcelona: Editorial Gustavo Gili, 1975.

MCCARTNEY, A.; PAQUETTE, D. Walking, listening, speaking: the soundwalking interactions project. In: THIBAUD, J; SIRET, D. Ambiances in action / Ambiances em acte(s) - International Congress on Ambiances, Montreal, 2012. International Ambiances Network, p.189-194. Disponível em: <https://goo.gl/LELG8b>. Acesso em: 12/11/2015.

MELLO, J B. F. O triunfo do lugar sobre o espaço. In: MARANDOLA, E.; OLIVEIRA, L. (orgs.). Qual o espaço do lugar? São Paulo: Perspectiva, p. 3368, 2014.
MERLEAU-PONTY, M. Fenomenologia da percepção. São Paulo: WMF Martins Fontes, 2011.

POCOCK, D. Sound and the geographer. Geography, Sheffield, n. 3, v. 74, p. 193-200, 1989. Disponível em: <http://goo.gl/q7w9Ra>. Acesso em: 26 ago. 2015.

PORTEOUS, J. D.; MASTIN, J. Soundscape. Journal of Architectural and Planning Research, Chicago, n. 3, v. 2, p. 169-186, 1985. Disponível em: < http://goo.gl/ia1sOU>. Acesso em: 26/08/2015.

RELPH, E. Reflexões sobre a emergência, aspectos e essência de lugar. In: MARANDOLA, E.; OLIVEIRA, L. (orgs.). Qual o espaço do lugar? São Paulo: Perspectiva, p. 17-32, 2014.

SALGUEIRO, T. B. Paisagem e geografia. Finisterra, Lisboa, n. 72. 2001. p. 37-53. Disponível em: <http://goo.gl/dnpY3Y>. Acesso em: 03/08/2015.

SCHAEFFER, P. Tratado de los objetos musicales. Madri: Alianza Editorial, 2003.

SCHAFER, M. A afinação do mundo: uma exploração pioneira pela história passada e pelo atual estado do mais negligenciado aspecto do nosso ambiente: a paisagem sonora. São Paulo: Editora Unesp, 2011

SEAMON, D. Geography of the lifeworld: movement, rest and encounter. Londres: Croom Helm, 1979.

SEEMANN, J. Cartografia e cultura: abordagens para a geografia cultural. In: ROSENDAHL, Z; CORREA, R. L. (Org.). Temas e caminhos da geografia cultural. Rio de Janeiro: Editora da UERJ, p 115-156, 2010.

SOKOLOWSKI, R. Introdução à fenomenologia. São Paulo: Companhia das Letras, 2014.

TORRES, M. A.; KOZEL, S.. Le paysage sonore de L'île des Valadares: perception et mémoire dans la construction de l'espace. Géographie et cultures, Paris, n. 78, p. 145-168, 2011. Disponível em: <http://goo.gl/bxe6gf>. Acesso em: 05/11/2015.

TUAN, Y. Espaço e lugar: a perspectiva da experiência. Londrina: Eduel, 2013.

Topofilia: um estudo da percepção, atitudes e valores do meio ambiente. Londrina: Eduel, 2012. 